\title{
Potências médias emergentes e reforma da arquitetura financeira mundial? Uma análise do BRICS no G20
}

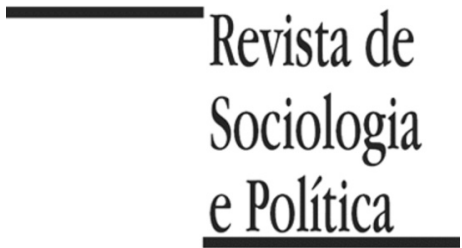

DOI: $10.1590 / 1678-987314225005$

\section{Leonardo Ramos}

\begin{abstract}
RESUMO
A partir de 2000, na cúpula de Okinawa, o sistema G7/8 começou um movimento de outreach, ou seja, tanto de "alcançar" aqueles que se encontravam fora quanto de "expandir" o sistema G7/8. Neste sentido, pela primeira vez países não-participantes do G8 foram envolvidos tanto em encontros do G8 quanto em consultas pré-cúpula. Neste processo a cúpula de Gleneagles, em 2005, foi um marco, pois nesta pela primeira vez há um documento conjunto emitido por Brasil, Índia, China, África do Sul e México (BICSAM) - Outreach Five ou Grupo dos Cinco (+5). Tal articulação entre tais países tendo como foco o sistema G7/8 vai ocorrer até a cúpula de L'Aquila, em 2009. Não obstante, como desde 2008 o G20 vem lidando com tais questões como um fórum de líderes e a partir de 2009 o BRIC passa a se reunir como coalizão, tal articulação paralela ao G8 perde sua relevância. Neste contexto, uma questão que surge diz respeito à relação entre BRICS e G20. Como se dá a ação de tal bloco emergente neste fórum? Qual seu impacto para as decisões tomadas no âmbito de tal fórum? Qual a importância da China neste processo? Questões deste tipo são relevantes uma vez que muitas abordagens sobre o G20 e sobre as potências médias emergentes falam a respeito da legitimidade e da representatividade do G20 sem, contudo, dar a devida atenção às potências médias emergentes, suas coalizões e formas de engajamento e articulação no âmbito do G20, e é neste contexto que se insere o presente artigo, que busca analisar a inserção e articulação do BRICS no âmbito do G20, suas potencialidades e limites.
\end{abstract}

PALAVRAS-CHAVE: BRICS; G20; governança global; FSB; G7/8.

Recebido em 23 de Agosto de 2013. Aprovado em 01 de Outubro de 2013.

\section{Introdução ${ }^{1}$}

\footnotetext{
${ }^{1}$ Versões prévias do presente artigo foram apresentadas no Workshop - "Desafios do BRICS após a Cúpula de Nova Déli". BRICS Policy Center, 18/09/ 2012, e no I Seminário Internacional das Potências Intermediárias, PUC Minas, 01/10/2012. Agradeço aos participantes de ambos os eventos pelos comentários feitos ao texto.

${ }^{2} \mathrm{O}$ conceito "sistema G7/8" diz respeito a duas questões: $(i)$ ao sistema de articulações que se configura ao redor de um processo mais amplo de elaboração e difusão de normas, ideologias e consensos - daí a ideia de sistema. Além disso, (ii) tal sistema passa por mudanças em sua configuração - G5, G6, G7 e G8 -
}

A partir de 2000, na cúpula de Okinawa, o sistema G7/8 ${ }^{2}$ começou um movimento de outreach, ou seja, tanto de "alcançar" aqueles que se encontravam fora quanto de "expandir" o sistema G7/8. Nesse sentido, pela primeira vez países não participantes do sistema G7/8 foram envolvidos tanto em encontros do G8 quanto em consultas pré-cúpula. Nesse processo, a cúpula de Gleneagles, em 2005, foi um marco, pois pela primeira vez há um documento conjunto emitido por Brasil, Índia, China, África do Sul e México (BICSAM) - Outreach Five ou Grupo dos Cinco (+5). Tal articulação ocorre até a cúpula de L'Aquila, em 2009; não obstante, como desde 2008 o G20 vem lidando com tais questões como um fórum de líderes e a partir de 2009 o BRIC passa a reunir-se como coalizão, tal articulação paralela ao sistema G7/8 perde sua relevância. Nesse contexto, uma questão que surge diz respeito à relação entre BRICS e G20. Como se dá a ação de tal coalizão emergente neste fórum? Qual seu impacto para as decisões tomadas no âmbito de tal fórum? Questões desse tipo são relevantes uma vez que muitas abordagens sobre o G20 e sobre as potências médias emergentes falam a respeito da legitimidade e da representatividade do G20 sem, contudo, dar a devida atenção às potências médias emergentes, suas coalizões e formas de engajamento e 
além de possuir estruturas sobrepostas - G5 e G7 de ministros de finanças e G6, G7 e G8 de líderes (além do G8+5 e do atual G20) daí a ideia de $\mathrm{G} 7 / 8$ (Ramos 2013).

\section{A origem do G20}

\footnotetext{
${ }^{3}$ Composto por Bélgica, Canadá, França, Alemanha, Itália, Japão, Holanda, Suécia, Suíça, Reino Unido e Estados Unidos - tendo status de observador BIS, OCDE, FMI e Comissão Europeia -, trata-se de um grupo formado nos anos 1960 para lidar com questões concernentes à política de empréstimos no âmbito do FMI.

${ }^{4}$ Para uma elucidativa diferenciação entre potências médias tradicionais e potências médias emergentes, ver Jordaan (2003).
}

articulação no âmbito do G20. É nesse contexto que se insere o presente artigo, buscando analisar a inserção e articulação do BRICS no âmbito do G20, suas potencialidades e limites.

Nota-se, como grande tema de convergência entre os países do BRICS no âmbito do G20, a necessidade de reforma das instituições financeiras internacionais (IFIs). Nesse sentido, a hipótese é a seguinte: um elemento que explica o destaque da reforma das IFIs na agenda do BRICS para o G20 consiste no fato deste ser o único tema realmente consensual entre os países de tal coalizão, o que se articula de maneira direta com a relevância das questões internas de cada país do BRICS, bem como com a ausência de um modelo alternativo compartilhado por tais atores. A estrutura do artigo será a seguinte: em primeiro lugar, será feito um breve histórico do G20, desde sua formação. Tal histórico é fundamental para que se possa, em segundo lugar, apresentar a evolução do G20, em especial a partir de 2008. Essas duas primeiras seções são fundamentais para que, em terceiro lugar, seja apresentado o cerne do argumento do artigo: em que medida o BRICS apresenta uma alternativa ao modelo vigente na arquitetura financeira mundial. Para tal será feita uma comparação entre a posição dos países do BRICS e do sistema G7/8 no âmbito do G20, ao longo das cúpulas de ambos agrupamentos. Por fim, serão feitas algumas considerações finais a partir dos dados produzidos em tal comparação.

Embora discussões sobre o estabelecimento de um lócus de discussão na área financeira que incluísse o $\mathrm{G}_{10} 0^{3}$ mais alguns dos principais países em desenvolvimento remeta ao encontro dos ministros de finanças e presidentes de bancos centrais do G7 em Halifax, em 1995 (Martinez-Diaz 2007), suas origens diretas datam da crise asiática em 1997-1998. Ora, tais questões encontram-se inseridas em um contexto mais amplo, no qual se percebe não apenas a "ascensão do resto" (Amsden 2004), mas também a emergência de uma série de iniciativas por parte dessas potências médias emergentes ${ }^{4}$. Em última instância, a crise asiática explicita algo que se tornaria notório nos anos 2000, mas que já emergia desde meados dos anos 1990, com a crise do México: a saber, o fato de que as questões relacionadas à arquitetura financeira mundial não poderiam ser resolvidas direta e exclusivamente pelo G7, sendo fundamental assim incorporar as potências médias emergentes em tais processos.

A questão que se colocava, nesse contexto, dizia respeito a duas questões: como e quem. Em função da crise asiática e de seus desdobramentos, houve várias articulações por parte dos ministros de finanças do G7 antes da reunião de Colônia. Grande parte de suas decisões acerca das reformas que se faziam necessárias derivavam de relatórios elaborados previamente pelo G22, um grupo informal articulado pelos Estados Unidos e que reunia países asiáticos e em desenvolvimento envolvidos na crise. Entre os elementos principais presentes na proposta apresentada em Colônia - em especial no que concerne ao fortalecimento e reforma das instituições financeiras internacionais - destacam-se: ( $i$ ) a criação do Fórum de Estabilidade Financeira (FSF); (b) a formalização do comitê interino do Fundo Monetário Internacional (FMI) como Comitê Monetário e Financeiro Internacional (IMFC); (iii) a proposta de criação de um mecanismo informal entre os países mais relevantes para a economia mundial, tendo como base o G22. Não obstante, em função de seu viés para a região do Pacífico, os europeus resistiram a tal ideia e a questão não foi resolvida em Colônia. 
${ }^{5} \mathrm{O}$ grupo era composto por Canadá, França, Itália, Alemanha, Japão, Estados Unidos, Reino Unido (ou seja, o G7), Argentina, Austrália, Brasil, China, Hong Kong, Índia, Indonésia, Malásia, México, Polônia, Rússia, Cingapura, África do Sul, Coréia do Sul e Tailândia.

${ }^{6}$ Foram assim incluídos os seguintes países: Bélgica, Chile, Costa do Marfim, Egito, Marrocos, Holanda, Arábia Saudita, Espanha, Suécia, Suíça e Turquia.

${ }^{7}$ Fazem parte do G20: Argentina, Austrália, Brasil, Canadá, China, França, Alemanha, Índia, Indonésia, Itália, Japão, Coreia do Sul, México, Rússia, Arábia Saudita, África do Sul, Turquia, Reino Unido, Estados Unidos e União Europeia. Além disso, o diretor do FMI, o presidente do Banco Mundial, o presidente do Banco Central Europeu e o responsável pelo IMFC e pelo Comitê de Desenvolvimento do FMI tem status de observador no G20.
Nesse sentido, uma primeira alternativa buscada foi o G22 ou Willard Group criado em 1998. Tal grupo foi criado pelos Estados Unidos e era composto por ministros de finanças e presidentes de bancos centrais de países desenvolvidos e em desenvolvimento ${ }^{5}$. Algumas reuniões foram feitas e surgiu, em 1999, a proposta de expansão do G22 para um G33, que incorporaria principalmente países do Oriente Médio, África e Europa ${ }^{6}$.

Algumas insatisfações ganharam destaque. Primeiro, no que diz respeito à necessidade, segundo alguns, de que tais reuniões fossem mais constantes, nos moldes do que ocorria com o G7; segundo, devido à insatisfação com relação ao número de participantes do processo, o que dificultaria significativamente o estabelecimento de um diálogo informal entre os países nas questões relacionadas ao sistema financeiro mundial. Foi então estabelecido o $\mathrm{G}_{20}{ }^{7}$, um grupo mais permanente - embora informal - no encontro de ministros de finanças do G7 em setembro de 1999. A ideia era estabelecer um fórum deliberativo, que trabalhasse com base no consenso de seus membros (Kirton 2005). Embora estivesse intimamente ligado à crise asiática do final dos anos 1990, também refletia mudanças significativas pelas quais a economia mundial vinha passando nas últimas décadas: a crescente inabilidade do sistema G7/8 de solucionar questões específicas da governança financeira global (como ficou claro, por exemplo, com relação à cúpula de Halifax, em 1995, e a crise do México de 1994; à cúpula de Birmingham, em 1998, e a crise asiática de 1997; e à cúpula de Áquila, em 2009, e a crise de 2008) aponta para a necessidade de incorporar as potências médias emergentes em tais processos. Nesse sentido, uma vez que as atenções são voltadas para a economia política global desde os anos 1970, é possível perceber a crescente relevância desses atores em termos de representatividade (Tabela 1). Além disso, a partir de alguns indicadores de comércio mundial, é possível notar que a importância sistêmica de tais países tem aumentado significativamente nos últimos dez a 15 anos, o que em certa medida acaba convergindo com o período de intensificação da crise do sistema G7/8.

Nota-se, assim, uma significativa "ascensão do resto" desde os anos 1970, em contraposição a uma diminuição da participação dos países do G8 na economia mundial: estes tiveram uma diminuição de aproximadamente $22 \% \mathrm{em}$ sua participação no total mundial das exportações de mercadorias e de $17 \%$ no tocante às exportações de serviços (Tabelas 2 e 3 ), com destaque para o período dos últimos dez anos. Em suma, o que se percebe é uma crescente relevância dos países emergentes para o funcionamento da economia política global, o que faz com que sua inclusão em certos mecanismos de governança a partir do final dos anos 1990 torne-se algo cada vez mais impreterível. Nesse sentido, o G20 foi criado inicialmente como uma reunião de ministros de finanças, o qual teve um papel relevante nos processos e deliberações após a crise asiática. Não obstante, um momento fundamental para tal agrupamento de países ocorreu após a crise de 2008, quando o G20 passou por um significativo processo de inflexão.

Tabela 1 - Produto Interno Bruto em comparação ao total mundial

\begin{tabular}{llllll}
\hline & $\mathbf{1 9 7 0}$ & $\mathbf{1 9 8 0}$ & $\mathbf{1 9 9 0}$ & $\mathbf{2 0 0 0}$ & $\mathbf{2 0 0 8}$ \\
\hline $\mathrm{G} 8$ & $71 \%$ & $64 \%$ & $68 \%$ & $66 \%$ & $55 \%$ \\
$\mathrm{G} 20^{\mathrm{a}}$ & $83 \%$ & $78 \%$ & $80 \%$ & $81 \%$ & $76 \%$ \\
$\mathrm{G} 5$ & $8 \%$ & $9 \%$ & $7 \%$ & $10 \%$ & $14 \%$ \\
G20 sem G8 & $12 \%$ & $14 \%$ & $12 \%$ & $15 \%$ & $21 \%$ \\
\hline
\end{tabular}

a. G20 sem União Européia

Fonte: UNSTATS (2010). 


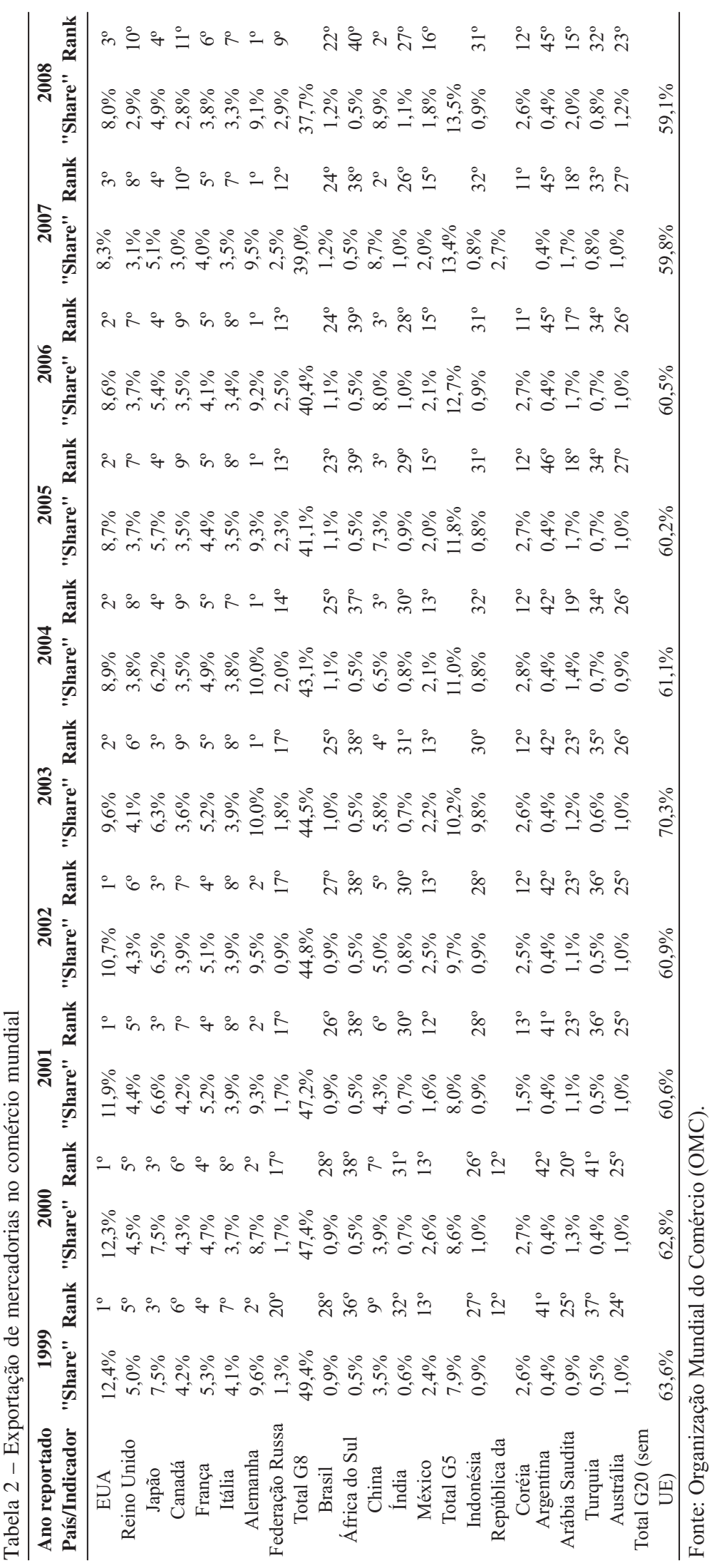




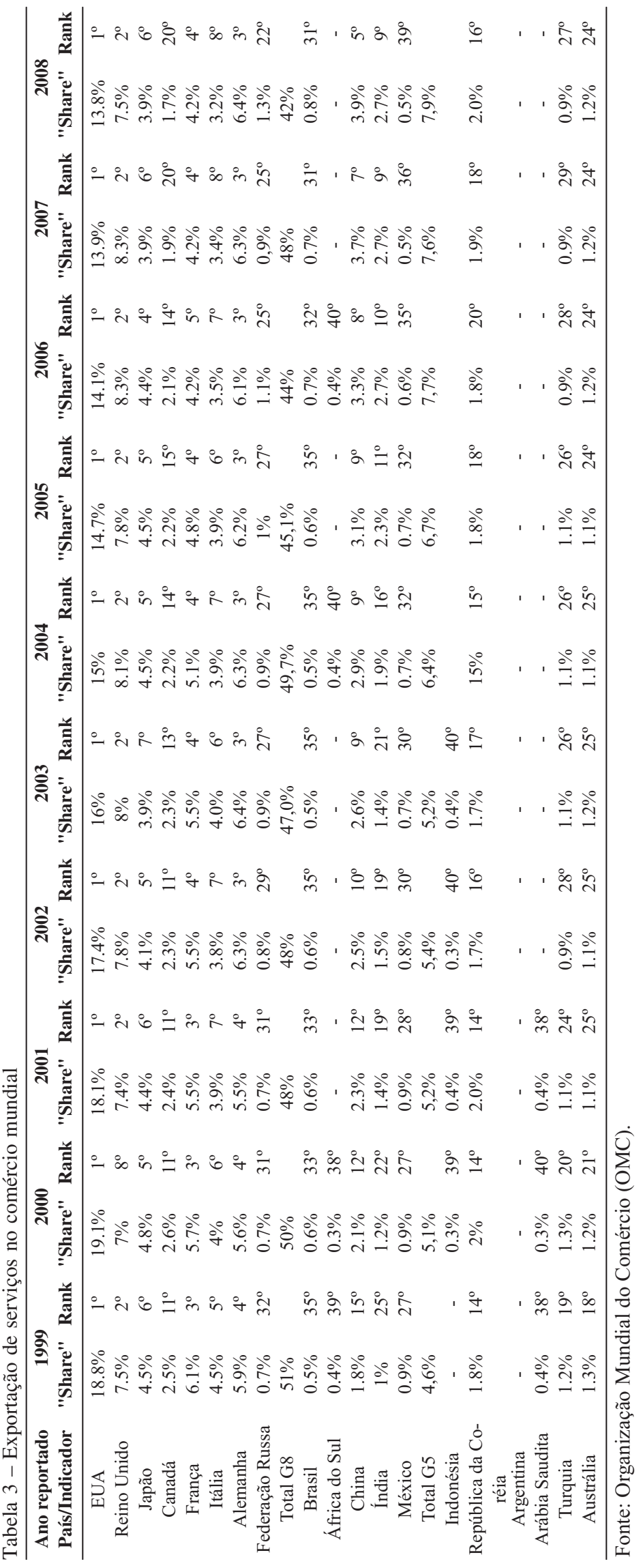




\section{A evolução do G20: As cúpulas a partir de 2008}

Em 2008, em um momento no qual se apresentava um processo de esgotamento do papel e do propósito do G20, tendo em vista a distância que se encontrava a crise para o qual ele fora criado, ocorreu uma nova crise, dessa vez com características distintas: uma crise não mais nos países em desenvolvimento como as anteriores, mas no centro e com proporções e desdobramentos mais amplos. Nesse contexto, foi dado um novo impulso ao G20, em larga medida pelas mesmas razões que levaram à sua criação: a necessidade de incorporação do "resto" tendo em vista a tentativa de construção de uma saída da crise. Nesse caso, o G20 reconfigura-se em termos mais robustos, passando a ocorrer, além da reunião de ministros de finanças, também uma reunião dos líderes de tais países.

Em 15 de novembro de 2008 ocorreu a primeira cúpula de líderes do G20, que, tendo como pano de fundo e causa fundamental a crise iniciada no mesmo ano, buscava "restaurar o crescimento global" (Group of Twenty 2008, §1), objetivo este que estaria presente em todas as cúpulas seguintes. Nesse sentido, desde a cúpula de Washington um ponto central era "uma visão compartilhada de que os princípios do mercado, o comércio aberto e os regimes de investimento e mercados financeiros efetivamente regulados promovam dinamismo, inovação e empreendedorismo, que são essenciais para o crescimento econômico, o emprego e a redução da pobreza"(idem, §2).

O diagnóstico acerca das causas subjacentes da crise era bem definido: a falta de mecanismos regulatórios suficientes para o setor das finanças no âmbito mundial assim como a falta de uma política de coordenação macroeconômica clara entre as maiores economias do mundo - desenvolvidas e emergentes deveriam ser objeto das atenções dos países no processo de superação da crise. Nesse sentido, em Washington, temas como (i) o uso de medidas fiscais para estimular a demanda interna - desde que mantida uma "política que conduza à sustentabilidade fiscal"; (ii) auxílio às economias emergentes; (iii) fortalecimento da transparência e responsabilidades das instituições financeiras privadas; e, associado a esse processo, (iv) um fortalecimento dos regimes regulatórios, o que também ajudaria a combater o processo de lavagem de dinheiro, foram temas destacados mas ainda sem uma indicação explícita acerca das políticas que seriam adotadas (idem, §7).

Além disso, foi discutida a questão da necessidade da reforma e capitalização das instituições financeiras mundiais. Neste caso duas questões merecem destaque: primeiro, a ênfase dada ao FMI como um ator relevante mas que necessita de passar por uma adequação face às mudanças ocorridas na economia política global nas últimas décadas; segundo, a ênfase dada na necessidade de reforma do Fórum de Estabilidade Financeira (FSF), para que este passasse a ter uma representatividade maior (idem, §9).

Na medida em que a crise mostrava-se cada vez mais disseminada e de difícil combate por cada Estado de maneira individual, na cúpula de Londres, em abril de 2009, foi reafirmado que uma "crise global exige uma solução global" (Group of Twenty 2009a, §2). Da mesma forma, nesse contexto de crise, os postulados neoliberais foram reafirmados: "acreditamos que o único alicerce seguro para a globalização sustentável e para a prosperidade crescente para todos é uma economia mundial aberta baseada em princípios de mercado, regulação eficaz e instituições globais robustas" (idem, §3). 
Segundo os países do G20, haveria a necessidade de restaurar a confiança no setor financeiro através do desenvolvimento de um marco regulatório e de supervisão mais eficaz. Isso seria fundamental para garantir a "disciplina de mercado" e "apoiar a competição e o dinamismo" (idem, §14). Buscando avançar nesse sentido, foi adotada em Londres a Declaração Reforçando o Sistema Financeiro, que entre outras questões destaca a criação do Conselho de Estabilidade Financeira (FSB) em substituição ao Fórum de Estabilidade Financeira (FSF). Enquanto este contava apenas com os países do sistema G7, aquele inclui os países do G20, ex-membros do FSF, Espanha, e a Comissão Europeia. Ora, em um contexto de crise como o daquele período, ficava claro que, para que uma reforma efetiva do sistema financeiro mundial pudesse ser implementada, era fundamental a inclusão dos países emergentes em vários fóruns e espaços de deliberação.

Tal fórum deveria operar em conjunto com o FMI, que em Londres foi capitalizado, juntamente com outras instituições financeiras, em cerca de US\$ 850 bilhões adicionais. Além disso, menção foi feita novamente à necessidade de reformar as instituições financeiras mundiais com o intuito de prevenir crises futuras e fortalecer tanto a relevância quanto a legitimidade de tais instituições. Nesse sentido, foi acordada a reforma das cotas do FMI e, em especial, enfatizada a necessidade de que fosse concluída a revisão das cotas até janeiro de 2011. No tocante ao Banco Mundial, também foi acordada a implementação das reformas discutidas a aprovadas em outubro de 2008 (idem, §20). Por fim, a partir de Londres, a questão do desenvolvimento dos países de baixa renda começou a ganhar um espaço maior nos documentos, juntamente com as questões relacionadas aos Objetivos do Milênio - com referência direta aos compromissos firmados anteriormente no âmbito do sistema G7/8 com relação a tais questões.

Quando da cúpula de Pittsburgh, nos dias 24 e 25 de setembro de 2009, a economia mundial dava sinais de estabilidade dos mercados financeiros e de interrupção da queda das atividades econômicas. Nesse sentido, menção foi feita a tal questão no intuito não apenas de gerar uma estabilidade ainda maior nos mercados financeiros, mas também de manter a cooperação entre os países do G20. Além disso, foi dado destaque mais uma vez à necessidade de, assim que possível, retirar a intervenção extraordinária dos Estados da economia "mantendo [...] o compromisso para com a responsabilidade fiscal" (Group of Twenty 2009b, §10). Ênfase foi dada no fato de que a recuperação da economia mundial demandaria certa colaboração em termos de políticas macroeconômicas, bem como o combate às práticas abusivas do mercado. Nesse sentido, houve, na cúpula de Pittsburgh, um comprometimento de que seriam desenvolvidas, "[...] até o final de 2010, normas acordadas internacionalmente para melhorar tanto a quantidade como a qualidade do capital bancário e desencorajar a alavancagem excessiva" (idem, §13).

Começa em Londres uma preocupação com as instituições financeiras sistemicamente importantes. Em Pittsburgh tal questão foi abordada, sendo decidido que até o final de 2010 mais detalhes das resoluções internacionais para lidar com tal questão deveriam ser desenvolvidas (idem, §13). Dando prosseguimento às discussões acerca da necessidade de reforma do FMI, os países do G20 comprometeram-se a transferir pelo menos 5\% das cotas de participação aos países emergentes e em desenvolvimento.

Na cúpula de Toronto, nos dias 26 e 27 de junho de 2010, foi reafirmada a relevância do G20 como fórum privilegiado de discussão das questões concer- 
nentes à economia global e à reestruturação da arquitetura financeira global, bem como os êxitos que teriam sido alcançados a partir das decisões tomadas nas cúpulas do G20 desde 2008. Em especial, ênfase foi dada à questão da sustentabilidade fiscal, tendo em vista as preocupações que emergiram a partir da crise na Zona do Euro. As economias avançadas comprometeram-se, assim, com a adoção de políticas de ajuste fiscal com o objetivo de diminuir ao menos pela metade seu déficit fiscal até 2013 e reduzir a relação dívida-PIB até 2016.

Foi reafirmada a importância de manter os mercados abertos e de combater o protecionismo, dando à OMC, OCDE e UNCTAD o papel de monitorar as políticas dos Estados e suas políticas com relação ao livre comércio. Em Toronto foi colocado que países com economias deficitárias devem aumentar a poupança interna enquanto mantém os mercados abertos e aumentam sua competitividade de exportação. Países superavitários, por sua vez, devem empreender reformas para reduzir sua dependência da demanda externa buscando, assim, fontes domésticas para seu crescimento. Além disso, países emergentes superavitários devem "aumentar a flexibilidade da taxa de câmbio buscando refletir assim seus fundamentos econômicos subjacentes [...]. Taxas de câmbio orientadas pelo mercado, que refletem os fundamentos econômicos subjacentes contribuem para a estabilidade econômica global" (Group of Twenty 2010a, §12).

Destaca-se nesse ponto a guerra "cambial" entre China e EUA, que continuaria tendo repercussões para a próxima cúpula.

Foi enfatizada também a necessidade de implementar-se reformas estruturais, nos países do G20, que garantam o crescimento. A agenda de reforma possui quatro pilares que em larga medida reproduzem e aprofundam questões que vinham sendo discutidas no âmbito do G20 desde a cúpula de Washington, em 2008: (i) fortalecimento do marco regulatório, baseado no novo regime global para liquidez e capital bancário desenvolvido pelo Comitê da Basileia de Supervisão Bancária (BCBS); (ii) criação de mecanismos de supervisão efetiva, com destaque para o papel do FSB e do FMI neste processo; (iii) implementação de um sistema para lidar com situações de instituições em crises financeiras, sem que isso gere ônus para os contribuintes em geral, reduzindo, assim, o risco moral; (iv) transparência internacional, com destaque para o combate à corrupção e à lavagem de dinheiro.

Assim como nas cúpulas anteriores, no que concerne às instituições financeiras mundiais, foi dada ênfase à necessidade de fortalecer a legitimidade, a credibilidade e a efetividade das mesmas, em especial do FMI e dos bancos multilaterais de desenvolvimento (BMD) - neste caso, destaque para o Banco Mundial. Em Pittsburgh houve um comprometimento de aumento do capital dos BMDs, o que ocorreu em Toronto (com um aumento de US\$ 350 bilhões, o que significa um aumento dos empréstimos desses bancos de US\$ 37 bilhões para US\$ 71 bilhões por ano (Tabela 4). Foi também endossada a reforma do Banco Mundial, que aumentaria o poder de voto dos países em desenvolvimento em 4,59\%, além do reforço da necessidade de completar o processo de reforma das cotas do FMI até a cúpula seguinte, em Seul.

Na cúpula de Seul, nos dias 11 e 12 de novembro de 2010, foi divulgado o Plano de Ação de Seul. Este incluía acordos na área de políticas macroeconômicas, como consolidação fiscal onde fosse necessário, estabelecimento de sistemas de taxas de câmbio mais orientadas pelo mercado e a abolição de desvalorizações competitivas das moedas; implementação de reformas estruturais que estimulem e sustentem a demanda global, promovam a criação de 
Tabela 4 - Aumento do capital dos Bancos Multilaterais de Investimento (BMD)

\begin{tabular}{|c|c|c|c|}
\hline BMD & Aumento de capital & $\begin{array}{l}\text { Empréstimos anu- } \\
\text { ais antes da crise } \\
\text { (em US\$ bilhões) } \\
\end{array}$ & $\begin{array}{l}\text { Empréstimos anu- } \\
\text { ais após a crise }{ }^{2}(\mathrm{em} \\
\text { US\$ bilhões) }\end{array}$ \\
\hline $\mathrm{AfDB}^{\mathrm{a}}$ & $200 \%$ & US $\$ 1,8$ & US\$6 \\
\hline $\mathrm{AsDB}^{\mathrm{b}}$ & $200 \%$ & US $\$ 5,8$ & US $\$ 10$ \\
\hline $\mathrm{EBRD}^{\mathrm{c}}$ & $50 \%$ & US $\$ 5,3$ & US $\$ 11$ \\
\hline $\mathrm{BID}^{\mathrm{d}}$ & $70 \%$ & US $\$ 6,7$ & US\$12 \\
\hline $\mathrm{BIRD}^{\mathrm{e}}$ & $30 \%$ & US $\$ 12,1$ & US\$15 \\
\hline $\mathrm{IFC}^{\mathrm{f}}$ & - & US $\$ 5,4$ & US\$17 \\
\hline Total & $85 \%$ & US\$37 & US\$71 \\
\hline
\end{tabular}

a. Banco de Desenvolvimento Africano

b. Banco Asiático de Desenvolvimento

c. Banco Europeu para Reconstrução e Desenvolvimento

d. Banco Interamericano de Desenvolvimento

e. Banco Internacional para Reconstrução e Desenvolvimento - parte do grupo do Banco Mundial

f. Corporação Financeira Internacional - parte do grupo do Banco Mundial

Notas: 1. 2000-2008; 2. 2012-2020.Fonte: Group of Twenty (2010a, §25; 2010b, §5)

empregos e aumentem o potencial de crescimento (Group of Twenty 2010c, $\S 7)$.

É interessante perceber a menção feita, em tal plano de ação, às questões relacionadas às taxas de câmbio. Além do problema já identificado por alguns com relação ao valor do yuan e seu impacto na economia mundial, na véspera da cúpula de Seul o Fed anunciou que, nos oito meses seguintes, irrigaria a economia estadunidense com US\$ 600 bilhões. Em última instância, o G20 não resolveu tal questão, mas apenas estabeleceu certos mecanismos para lidar com a mesma na primeira metade de 2011, mediante o Processo de Avaliação Mútua (MAP) acordado em Seul.

Dando sequência no que já vinha sendo objeto de discussão em Pittsburgh e Toronto, em Seul foi acordada uma mudança na política de cotas do FMI (Tabela 5). Foi também reafirmado o papel de destaque deste na reconstrução da arquitetura financeira mundial; nesse processo, FSB e BCBS também seriam centrais.

Em consonância com as questões levantadas em Toronto, foi acordado, em Seul, o chamado "Consenso de Seul", no qual se destacam os seguintes princípios: (i) importância do crescimento econômico inclusivo e sustentável para a redução da pobreza e desenvolvimento dos países de baixa renda; (ii) ausência de uma única fórmula para o desenvolvimento. Assim, os países devem trabalhar como parceiros, respeitando as políticas adotadas e desenvolvidas domesticamente como fundamentais para o êxito da estratégia de desenvolvimento; (iii) as ações devem priorizar questões globais ou regionais que demandam ações coletivas e possuam o potencial para gerar um impacto de transformação; (iv) ênfase no papel do setor privado na geração de empregos e riqueza, e nesse sentido na criação de um ambiente que gere possibilidades para a expansão e para o investimento privados; ( $v)$ maximizar as possibilidades de complementaridade na busca pelo desenvolvimento, dando ênfase para as áreas nas quais o G20 possua vantagem comparativa e possa, assim, agregar no processo de crescimento sustentável; ( $v i$ ) foco nos resultados tangíveis de impacto significativo para remoção dos obstáculos ao crescimento dos países em desenvolvimento (idem, 2010d). 
Tabela 5 - Distribuição de cotas - FMI

\begin{tabular}{|c|c|c|c|c|}
\hline \multirow{2}{*}{$\begin{array}{l}\text { Ano } \\
\text { Cota/voto }\end{array}$} & \multicolumn{2}{|c|}{2009} & \multicolumn{2}{|c|}{$2010^{1}$} \\
\hline & Cotas & Votos & Cotas & Votos \\
\hline EUA & $17,09 \%$ & $16,74 \%$ & $17,41 \%$ & $16,48 \%$ \\
\hline Reino Unido & $4,94 \%$ & $4,85 \%$ & $4,22 \%$ & $4,02 \%$ \\
\hline Japão & $6,12 \%$ & $6,01 \%$ & $6,46 \%$ & $6,14 \%$ \\
\hline Canadá & $2,93 \%$ & $2,88 \%$ & $2,31 \%$ & $2,21 \%$ \\
\hline França & $4,94 \%$ & $4,85 \%$ & $4,22 \%$ & $4,02 \%$ \\
\hline Itália & $3,24 \%$ & $3,19 \%$ & $3,16 \%$ & $3,02 \%$ \\
\hline Alemanha & $5,98 \%$ & $5,87 \%$ & $5,59 \%$ & $5,31 \%$ \\
\hline Federação Russa & $2,73 \%$ & $2,69 \%$ & $2,71 \%$ & $2,59 \%$ \\
\hline Total G8 & $47,97 \%$ & $47,08 \%$ & $46,08 \%$ & $43,79 \%$ \\
\hline Brasil & $1,40 \%$ & $1,38 \%$ & $2,32 \%$ & $2,22 \%$ \\
\hline África do Sul & $0,86 \%$ & $0,85 \%$ & $0,64 \%$ & $0,63 \%$ \\
\hline China & $3,72 \%$ & $3,65 \%$ & $6,39 \%$ & $6,07 \%$ \\
\hline Índia & $1,91 \%$ & $1,88 \%$ & $2,75 \%$ & $2,63 \%$ \\
\hline México & $1,45 \%$ & $1,43 \%$ & $1,87 \%$ & $1,80 \%$ \\
\hline Total G5 & $9,34 \%$ & $9,19 \%$ & $13,97 \%$ & $13,35 \%$ \\
\hline Indonésia & $0,96 \%$ & $0,95 \%$ & $0,96 \%$ & $0,95 \%$ \\
\hline $\begin{array}{l}\text { República da Co- } \\
\text { réia }\end{array}$ & $1,35 \%$ & $1,33 \%$ & $1,80 \%$ & $1,73 \%$ \\
\hline Argentina & $0,97 \%$ & $0,96 \%$ & $0,67 \%$ & $0,66 \%$ \\
\hline Arábia Saudita & $3,21 \%$ & $3,16 \%$ & $2,10 \%$ & $2,01 \%$ \\
\hline Turquia & $0,55 \%$ & $0,55 \%$ & $0,98 \%$ & $0,95 \%$ \\
\hline Austrália & $1,49 \%$ & $1,47 \%$ & $1,38 \%$ & $1,33 \%$ \\
\hline $\begin{array}{l}\text { Total G20 (sem } \\
\text { UE) }\end{array}$ & $65,84 \%$ & $64,69 \%$ & $67,94 \%$ & $64,77 \%$ \\
\hline
\end{tabular}

Nota: 1. Decidido em novembro de 2010, mas seria implementado apenas em 2012.Fonte: FMI

Devido aos desdobramentos relacionados ao desemprego nos países industrializados bem como à crise do Euro - e da Grécia em particular, nos dias 3 e 4 de novembro de 2011 ocorreu a cúpula de Cannes, no mesmo grau de intensidade das cúpulas de Washington e Londres, anos antes. As questões vinculadas à crise do modelo de globalização até então vigente se expressam também em Cannes. Além disso, chegou-se a um acordo sobre um "Plano de Ação para o Crescimento e o Emprego" (Group of Twenty 2011c). Nesse caso, diferentemente do que ocorreu em Seul, quando a ênfase era no crescimento dos países mais pobres, a crise do Euro leva o G20 a preocupar-se com os países industrializados e com os países emergentes em um plano que enfatiza a necessidade da restauração da confiança para o crescimento e a consolidação fiscal.

Houve também o compromisso do G20 com o estabelecimento, assim que possível, de um sistema cambial determinado pelas forças de mercado. "Países com grandes superávits em conta corrente se comprometem com reformas para aumentar a demanda interna, conjugada com uma maior flexibilidade cambial"

8 "Congratulamos as mudanças recentes no regime cambial da Rússia que permite ao Rublo se mover de uma forma mais próxima das forças de mercado e a determinação da China em aumentar a flexibilidade da taxa de câmbio de uma maneira consistente com os fundamentos de mercado" (Group of Twenty 2011c, §3). (Group of Twenty 2011b, §5), o que é ume referência direta a países como a China, por exemplo. Nesse caso, menção explícita foi feita às ações de China e Rússia $^{8}$. Com a crescente importância das potências médias emergentes por um lado e a crise do Euro de outra, foi destacada a necessidade de ampliação da cesta de moedas que compõem os Direitos Especiais de Saque (SDR) ${ }^{9}$, o que ocorrerá em 2015. Além disso, foi destaca a importância do FMI na resolução das crises financeiras contemporâneas (Group of Twenty 2011a, §13 e $16-20 ; 2011 b, \S 8)$. Na verdade, é importante destacar o fato de que tal acordo em torno de temas até então polêmicos em Toronto e Seul ocorreu em grande 
${ }^{9}$ De maneira geral, trata-se da "moeda" do FMI ou, mais especificamente, da unidade contábil utilizada pelo Fundo desde 1969 Atualmente sua cotação dá-se com base em uma cesta de moedas composta por: Dólar estadunidense, Iene, Libra Esterlina e Euro.

\footnotetext{
${ }^{10}$ Fundo Monetário Internacional - http://www.imf.org.
}

medida devido à preocupação generalizada acerca da delicada e urgente situação da Grécia (Cooper 2011). Além disso, foi dada sequência nas discussões acerca da regulação e supervisão do sistema financeiro, com destaque para o tratamento das questões concernentes às firmas financeiras "muito grandes para quebrar" (Group of Twenty 2011a, §10-11).

A cúpula seguinte do G20 ocorreu nos dias 18 e 19 junho de 2012, em Los Cabos. Um fato interessante ocorreu no dia 17 de junho: um dia antes da cúpula de líderes, os ministros de finanças do G7 reuniram-se também em Los Cabos e publicaram uma nota sobre as eleições ocorridas na Grécia. Em tal nota, foi reafirmado o interesse do G7 de que a Grécia permaneça no Euro bem como de trabalho conjunto dos países do G7 com a Grécia na superação da crise (G7 Finance Ministers 2012). Tal questão foi objeto das atenções na cúpula, onde foi reafirmado o compromisso do G20 com a estabilidade e integridade da União Econômica e Monetária da UE (Group of Twenty 2012a, §6, 11) - o que foi reafirmado pelos ministros de finanças do $\mathrm{G} 20 \mathrm{em}$ sua reunião alguns dias depois (G20 Finance Ministers 2012).

A crise do modelo neoliberal de globalização também se expressa em tal cúpula, pois, assim como em Cannes no ano anterior, a preocupação inicial expressa na declaração final é com a "promoção do crescimento e dos empregos" (Group of Twenty 2012a, §2), com o reconhecimento explícito dos limites e da fragilidade da recuperação econômica mundial. Nesse sentido, em Los Cabos foi acordado um Plano de Ação de Los Cabos para Crescimento e Emprego" (Group of Twenty2012b) bem como estendido em um ano a Força Tarefa do G20 para Emprego.

Tendo em vista a recuperação econômica, a sustentabilidade fiscal é vista como fundamental. Assim, a importância dos comprometimentos feitos em Toronto com relação a tal questão foi enfatizada, levando em consideração as circunstâncias específicas de cada país. No tocante à arquitetura financeira mundial, foram retomadas as discussões feitas anteriormente, em abril, na reunião entre o IMFC e os ministros de finanças e presidentes de Banco Central do G20 (Joint Statement by the International Monetary and Financial Committee and the Group of 20 Finance Ministers and Central Bank Governors on IMF Resources 2012). Assim, foi enfatizada a necessidade de aumentar os recursos do FMI - neste caso, em mais de US $\$ 450$ bilhões - e reafirmado o compromisso com a implementação, na sua totalidade, das reformas nas cotas do FMI acordadas em 2010 - o que era uma demanda por parte das potências médias emergentes (Group of Twenty 2012a, §32-34).

Alguns países emergentes passaram por uma queda no crescimento no ano de $2012^{10}$. Assim, em Los Cabos tal questão foi mencionada bem como a legitimidade de políticas fiscais e monetárias que garantam a manutenção do crescimento mediante principalmente o fortalecimento da demanda doméstica. Contudo, tais ações devem ocorrer visando a liberalização futura. Assim, no tocante às questões monetárias, o G20 reafirmou seu "comprometimento com uma mudança [...] para um sistema de taxas de câmbio determinadas pelo mercado [...], evitando persistentes desalinhamentos das taxas de câmbio e refreando as desvalorizações competitivas das moedas" (idem, §8). Nesse sentido, mais uma vez foram destacadas as ações chinesas de reforma de seus regime e política cambiais. Dito isso, passemos agora à ação do BRICS no âmbito do G20. 


\section{Nova arquitetura financeira mundial? BRICS, G8, G20}

O termo BRIC é originário de um acrônimo criado por Jim O'Neill, economista do Golden Sachs. A mesma instituição financeira, em um estudo de 2003, demonstrou que apesar de na época Brasil, Rússia, Índia e China não representarem 15\% do PIB do G6 (EUA, Grã Bretanha, Alemanha, França, Itália e Japão), os quatro países tinham potencial de igualar o PIB das seis maiores economias industriais avançadas nas próximas quatro décadas (Armijo 2007). Seja como for, desde a criação do acrônimo, o BRIC (posteriormente BRICS com a adesão da África do Sul), principalmente devido à China, tem aumentado a sua participação no PIB mundial, o que colocou em pauta a necessidade de reformular os organismos de governança mundial para abarcar o real peso desses países (Jesus 2012). Assim, o que era no início apenas um acrônimo transformou-se "[...] em um quadro diplomático para a criação de um bloco de quatro países emergentes, aparentemente dotados de vocação, sobretudo econômica, para propor alternativas ao mundo supostamente conservador do atual G7" (Almeida 2010, p. 132).

Porém, essa transformação do BRICS ocorreu ao longo dos últimos dez anos, passando por sua primeira reunião de ministros de relações exteriores em 2006, o que marcou a incorporação do termo BRIC à política externa de Brasil, Rússia, Índia e China, para finalmente incorporar a África do Sul na cúpula de Sanya, em 2011, formando assim o BRICS. Após a incorporação oficial da África do Sul ao grupo, ocorreram mais duas cúpulas, a de 2012, em Nova Délhi, Índia, e a de 2013 em Durban, na África do Sul.

Fundamental, nesse processo, é perceber que, de alguma forma, tal articulação sul-sul busca ampliar sua inserção na governança econômica global: começando como BICSAM (Brasil, Índia, China, África do Sul e México) no âmbito do sistema G7/8, a partir de 2005, passando pela primeira reunião dos chefes de Estado dos BRICS durante a cúpula do G8 em Hokkaido, em 2006, e consolidando-se como BRIC(S) no âmbito do G20 a partir de 2008, é possível perceber certo engajamento na busca de certos objetivos (Lukov 2012). Após a crise financeira de 2008 e, em especial, com seus desdobramentos na zona do Euro, as articulações e o papel do BRICS no G20 ganharam uma relevância ainda maior, tendo em vista a demanda, por parte dos países da Europa, de ajuda econômica dos países em desenvolvimento.

Embora não haja posições claramente convergentes, é possível perceber uma certa tendência, ainda incipiente e frágil, em direção à formação de duas grandes coalizões no âmbito do G20 - ambas permeadas de clivagens e contradições internas (Ramos et. al. 2012, p. 23): "De um lado, China, Brasil e os "'novos emergentes'", incluindo a Argentina (com a Coréia do Sul em uma posição de centro). Uma estratégia dos EUA para tentar cooptar países como o Brasil, por exemplo, é acusar a China de práticas cambiais desonestas ou manipuladas. (idem) Em contraposição, e tendo em vista inclusive certas políticas cambiais unilaterais adotadas pelos EUA, a China acaba liderando determinadas propostas de alternativas monetárias ao dólar como reserva internacional propostas que contam com certo apoio brasileiro. Além disso, a China responde às críticas dos EUA destacando a necessidade de que os países desenvolvidos implementem os compromissos feitos em Toronto - redução pela metade dos déficits até 2013 e estabilização ou redução da dívida em relação ao PIB até 2016";. Soma-se a tais questões o fato de que os países emergentes são a favor do controle de capitais e contra a proposta dos países desenvolvidos para que haja uma redução do ritmo de acumulação de reservas internacionais (Bra- 
${ }^{11}$ Para um argumento distinto, ver Schirm (2012). sil vai defender controle de capitais 2010; BRICS rejeitam reduzir acumulação de reservas 2011). Tal crítica dos países desenvolvidos é voltada para a China, pois as reservas dos BRICS somam cerca de US\$ 4 trilhões, dos quais US\$ 3,2 trilhões correspondem à China.

Do outro lado, parte significativa dos países desenvolvidos (parte do G7) encontravam-se em uma posição relativamente comum até a crise da Grécia. A partir de então, percebe-se certa fragmentação de tal coalizão entre EUA e União Europeia. Os EUA colocam-se contrários à regulamentação financeira, em consonância com os interesses do setor financeiro estadunidense, e favoráveis às políticas monetárias expansivas. Já a União Europeia, liderada pela Alemanha, é a favor de certos controles dos fluxos de capitais, com maiores ajustes fiscais monitorados pelo FMI na periferia da zona do Euro. Nesse caso, o Brasil acaba aliando-se à posição dos EUA, defendendo que os países desenvolvidos adotem políticas de estímulo à economia, e não políticas de contenção fiscal (Brasil e EUA se aliam no G-20 a favor de estímulos 2011). Embora certa convergência possa ser percebida novamente em Los Cabos, nota-se assim uma fragmentação do G7, em especial no que concerne à posição de EUA, Alemanha, França e Reino Unido com relação a alguns temas específicos. Embora seja possível perceber certa falta de convergência dos países do BRICS nos fóruns globais em geral (Kahler 2013), no que concerne especificamente ao G20 tal questão é relevante porque se percebe, ao longo do processo de articulação do BRICS nessas questões (remontando ao BICSAM, em 2005) uma maior coerência do que no G7, em especial a partir de Cannes ${ }^{11}$. Não obstante, tal coerência expressa-se de maneira mais significativa em áreas específicas, com determinadas consequências para os debates acerca das reais alternativas apresentadas por tais países.

Neste sentido, um elemento extremamente elucidativo para analisar-se a relação BRICS, G7/8 e G20 diz respeito ao processo de implementação, país por país, das recomendações acordadas no âmbito do G20. O Financial Stability Board (FSB) é o responsável por tal monitoramento, e nesse sentido, em outubro de 2011, foi criado o Coordination Framework for Implementation Monitoring (CFIM) para executar tal tarefa. Desde então, relatórios têm sido produzidos cujos dados seguem sistematizados na Tabela 06 :

Alguns esclarecimentos são necessários neste ponto. Na Tabela 6, a maior parte do "não se aplica" (N.A.) concernente ao BRICS diz respeito a questões que realmente não se aplicam, seja porque não se trata de uma questão substantiva para esses países (inexistência de instituições financeiras sistematicamente importantes - SIFIs - por exemplo), seja porque a recomendação em questão diga respeito a algo já implementado anteriormente por esses países (nível de alavancagem e implementação de determinadas questões do acordo da Basiléia II e III, por exemplo). No que diz respeito ao G7, a questão é de outra natureza: a maior parte do "não se aplica" diz respeito a argumentações dadas pelos países de que sua legislação já aborda, de alguma maneira, as questões levantadas pelas recomendações - mesmo embora tenham sido o epicentro da crise com tais arranjos normativos domésticos. Ou seja, embora haja o reconhecimento do problema, quando possível, há a tentativa de evitar mudanças por parte dos países desenvolvidos, o que demonstra os limites do G20 para gerar transformações mais profundas na arquitetura financeira mundial. Além disso, a partir de tais questões surge uma questão sobre a real diferença entre os modelos do BRICS e do G7. 
Tabela 6 - FSB - Implementação das recomendações do G20

\begin{tabular}{llll}
\hline & OK & Discussão/implementação & N.A. \\
\hline BRICS & $23,5 \%$ & $30 \%$ & $26 \%$ \\
G7 & $33,2 \%$ & $30,7 \%$ & $30 \%$ \\
\hline
\end{tabular}

Fonte: Financial Stability Board (2012).

Segundo a declaração final do G8, na cúpula de Camp David em 2012, "nos comprometemos a adotar todos os passos necessários para fortalecer e revigorar nossas economias e combater tensões financeiras, reconhecendo que as medidas corretas não são as mesmas para cada um de nós" (Group of Eight 2012, §4). Ou seja, a divergência entre os países desenvolvidos - em especial EUA e Alemanha - aponta para o fato de que uma marca da crise é a percepção de que, até o momento, não há uma alternativa vista como viável para todos - diferentemente do que ocorria, por exemplo, com o Consenso de Washington. Ao que parece, o êxito de modelos alternativos ao neoliberal tout court abriram espaço em termos de modelos predominantes. De maneira geral, embora seja possível afirmar que os modelos dos países do BRICS baseiam-se em instituições econômicas distintas daquelas que formam a base do modelo neoliberal anglo-saxão (Nölke 2012), é importante não perder de vista a relação entre o modelo de capitalismo que vem sendo construído/expresso nas declarações e posicionamentos do BRICS e as características particulares de cada um dos BRICS.

A despeito de determinadas críticas constantes em seus posicionamentos em fóruns como o G20, as respostas dadas por tais países têm assumido um caráter ambivalente e, em alguns casos, híbrido, incorporando elementos neodesenvolvimentistas e neoliberais ao mesmo tempo (Morais \& Saad-Filho 2011; Ramos et al. 2012; Schmalz \& Ebenau 2012). No longo prazo, qual o real potencial transformativo de tal coalizão? Questões dessa natureza ajudam a explicar também certa inflexão nas demandas e ações desse grupo de países, em especial no que concerne ao G20 e à convergência de determinados interesses entre a coalizão e certos atores do G7. Nesse sentido, uma vez que a crise estabilize-se nos países desenvolvidos, existe a possibilidade de que estes usem o G20 para inserir as potências médias emergentes na ordem mundial vigente, esvaziando ainda mais as possibilidades de inserção diferenciada de tais países.

A Tabela 7, elaborada a partir das declarações do BRICS (BICSAM 2008), G20 e G8 (e declarações das reuniões de ministros de finanças do G7), e tendo como ponto de comparação o impacto de BRICS e sistema G7/8 nas

${ }^{12}$ Nesse ponto um esclarecimento faz-se necessário: as células da tabela que se encontram em branco dizem respeito a situações nas quais as declarações do BRICS e do sistema G7/8 não são explícitas com relação ao tema em questão. declarações do G20, demonstra um pouco desta questão ${ }^{12}$ : em cinco temas considerados relevantes para a arquitetura financeira mundial e de uma forma ou de outra presentes nas declarações e posicionamentos de tais fóruns, apenas no que concerne à reforma das instituições financeiras internacionais (IFIs) os interesses do BRICS foram prevalecentes no âmbito do G20 mas, mesmo nesse caso, alguns deles ainda não foram implementados - vide a reforma do FMI. Nos demais, percebe-se a predominância da convergência, o que expressa a relevância do G7 e de suas posições na resposta à crise. Ou seja, mesmo que seja possível afirmar a emergência, no âmbito no G20, de um "regime de desenvolvimento liberal global" no qual as potências médias emergentes possuem uma importância significativa (Cammack 2012), parece permanecer válida a afirmação de Jim Flaherty, ministro de finanças do Canadá em 2010: "[...] com relação ao futuro do G7, '[...] penso que nosso encontro tem reafir- 
Tabela 7 - Declarações comparadas: BRICS, sistema G7/8, G20 (2008-2012)

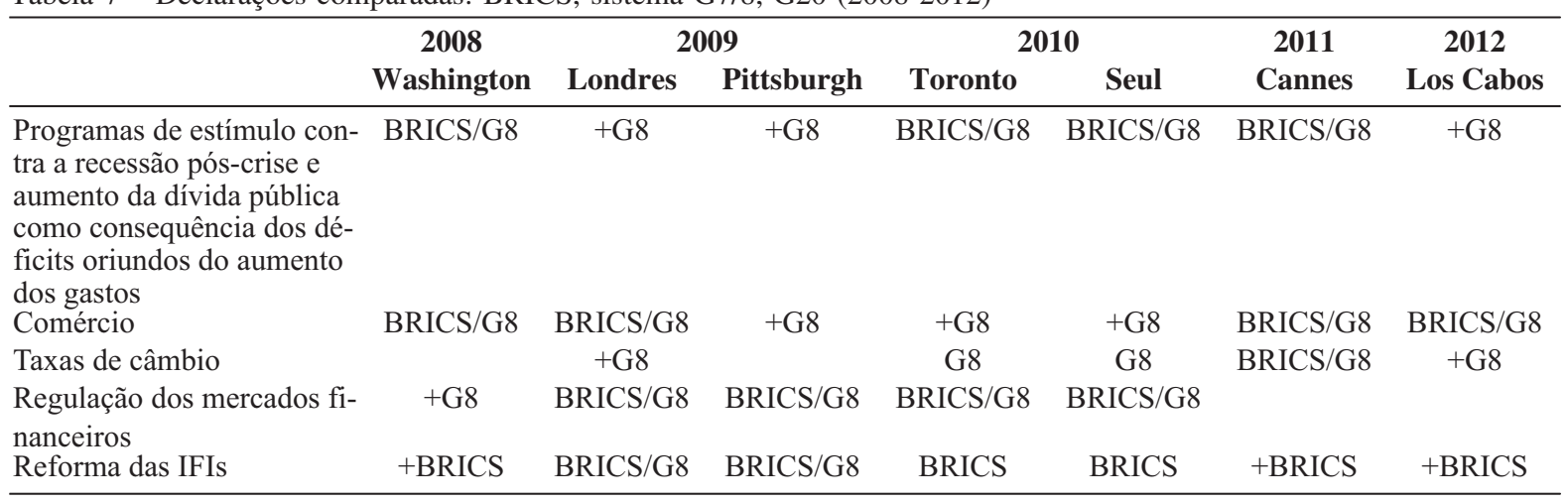

Legenda:

G8 - Predomínio da posição do sistema G7/8

+G8 - Predomínio da posição do sistema G7/8, com pequena convergência do BRICS

BRICS/G8 - Concordância das posições de BRICS e sistema G7/8

+BRICS - Predomínio da posição do BRICS, com pequena convergência do sistema G7/8

BRICS - Predomínio da posição do BRICS

Fonte: $\mathrm{O}$ autor.

mado o papel já provado do G7 como o primeiro a responder em uma crise econômica [...]" (Canada 2010, p. 2).

\section{Conclusões}

Em última instância, os dados supracitados apontam para o fato de que, embora haja certa convergência, esta tem gerado, na prática, um modesto aumento de influência por parte do BRICS no âmbito o G20. Mas até que ponto os países da coalizão estão dispostos a arcar com os custos da liderança que almejam (Patrick 2010)? Tais países não demonstram o desejo de uma alteração radical na estrutura de governança econômica global. Nesse ponto, importam as dinâmicas internas de cada um dos países, pois podem afetar tanto a possibilidade de cooperação entre os países da coalizão no longo prazo quanto de arcar com os custos do protagonismo ambicionado. Além disso, embora o BRICS tenha avançado em certas ações concretas, a opção pela autonomia dos seus membros, bem como pela informalidade tem colocado limites para a promoção de uma agenda comum que realmente se apresente como uma alternativa viável. Nesse contexto, as discrepâncias econômicas entre China e os demais países do BRICS (e as tensões oriundas de tal relação) bem como as divergências internas no que concerne às outras questões além da reforma das instituições financeiras internacionais - como por exemplo a posição divergente entre China e Rússia, de um lado, e Brasil, Índia e África do Sul, de outro, no que diz respeito à reforma do Conselho de Segurança da ONU - são elementos que atestam tais limites (Pant 2013).

Por fim, qual a visão do BRICS para o futuro do G20, ou qual G20 estaria mais próximo dos interesses do BRICS? Seria uma maior formalização desse fórum? Ao que parece, as demandas de reforma das IFIs, avanço na Rodada Doha, criação do FSB e ampliação do BCBS, por exemplo, apontam que a proposta seria outra, mais próxima do esquema de funcionamento do sistema G7/8 - ou seja, há uma tendência a ver o G20 como um vetor do processo de transnacionalização do Estado que opera como uma "rede de redes" (Gill 1990, p. 142); um "centro de irradiação, de difusão, de persuasão" em escala global. 
Ou seja, como dito anteriormente, o BRICS demanda uma maior participação na governança global sem, necessariamente, uma intensificação dessa governança global.

Leonardo Ramos (lcsramos@pucminas.br) é Doutor em Relações Internacionais pela PUC-Rio e professor do Departamento de Relações Internacionais da Pontifícia Universidade Católica de Minas Gerais (PUC-Minas).

\section{Referências}

Almeida, P.R. 2010. O BRIC e a substituição de hegemonias. In R. Baumann, ed. O Brasil e os demais BRICs: comércio e política. Brasília: CEPAL.

Armijo, L.E. 2007. The BRICs Countries as Analytical Category: Insight or mirage? Asian Perspective,31(4), pp. 1-42.

Amsden, A.H. 2004. A ascensão do "resto": os desafios ao ocidente de economias com industrialização tardia. São Paulo: Unesp.

Cammack, P. 2012. The G20, the Crisis, and the Rise of Global Developmental Liberalism. Third World Quarterly, 33(1), pp. $1-16$.

Cooper, A.F. 2011. Up Close at the Cannes Summit. Disponível em: http:///www.g20.utoronto.ca/analysis/111105-cooper. html. Acesso em: 5.jun.2014.

Gill, S. 1990. American Hegemony and the Trilateral Commission. Cambridge: Cambridge University Press.

Jesus, D.S.V. 2012. De Nova Iorque a Nova Délhi: informalidade, flexibilidade e independência no BRICS. In J.P. Nogueira, ed. Os BRICS e as transformações na ordem internacional. Rio de Janeiro: PUC-Rio.

Jordaan, E. 2003. The Concept of a Middle Power in International Relations: Distinguishing between emerging and traditional middle powers. Politikon,30(1), pp. 165-181.

Kahler, M. 2013. Rising Powers and Global Governance: Negotiating change in a resilient status quo. International Affairs,89 (3), pp. 711-729.

Kirton, J. 2005. Toward Multilateral Reform: The G20's contribution. In A.J. Venables; J. English; R. Thakur, eds. Reforming from the Top: A leaders' 20 summit. Tokyo: United Nations University.

Lukov, V. 2012. A Global Forum for the New Generation:The role of the BRICS and the prospects for the future. BRICS Information Centre. Disponível em: http://www.brics.utoronto.ca/analysis/Lukov-Global-Forum.html. Acesso em: 5.jun.2014.

Martinez-Diaz, L. 2007. The G20 after Eight Years: How effective a vehicle for developing- country influence? The Brookings Institution, Global Economy and Development, Working Paper n. 12, pp. 1-31.

Morais, L.; Saad-Filho, A. 2011. Da economia política à política econômica: O novo-desenvolvimentismo e o governo Lula. Revista de Economia Política,31(4), pp. 507-527.

Nölke, A. 2012. The Rise of the 'B(R)IC Variety of Capitalism': Toward a new phase of organized capitalism? In H. Overbeek.; B. Apeldoorn, eds. Neoliberalism in Crisis.Basingstoke: Palgrave Macmillan.

Pant, H.V. 2013. The BRICS Fallacy. The Washington Quarterly,36(3), pp. 91-105.

Patrick, S. 2010. Irresponsible Stakeholders? The difficulty of integrating rising powers. Foreign Affairs,89(6).

Ramos, L. 2013. Hegemonia, revolução passiva e globalização: o sistema G7/8. Belo Horizonte: PUC Minas.

Ramos, L.; Vadell, J.; Saggioro, A.; Fernandes, M. 2012.A governança econômica global e os desafios do G-20 pós crise financeira: análise das posições de Estados Unidos, China, Alemanha e Brasil. Revista Brasileira de Política Internacional,55(2), pp. 10-27.

Schirm, S.A. 2012. Global Politics are Domestic Politics: A societal approach to divergence in the G20. Review of International Studies,39(3), pp. 685-706.

Schmalz, S.; Ebenau, M. 2012. After Neoliberalism? Brazil, India, and China in the global economic crisis. Globalizations, 9 (4), pp. 487-501.

Woods, N. 2006. The Globalizers: The IMF, the World Bank, and their borrowers. Ithaca: Cornell University Press.

\section{Outras fontes}

Canada. Department of Finance. 2010. Financial Reform, Development, Haiti on Agenda at "Back to Basics". G7 Meeting. Iqualuit, 5.Feb. Disponível em: http://www.fin.gc.ca/n10/10-010-eng.asp. Acesso em: 5.jun.2014.

Financial Stability Board. 2012. National/Regional Responses on Progress in the Implementation of the G20 Recommendations. 19.jun. Disponível em: http://www.financialstabilityboard.org/publications/r_120619nr.htm. Acesso em: 5.jun.2014.

G7 Finance Ministers. 2012. Statement of G7 Finance Ministers. Toronto, 17.jun. Disponível em: http://www.g8.utoronto.ca/ finance/fm120617.htm. Acesso em: 5.jun.2014. 
G20 Finance Ministers. 2012. Statement: the G20 welcomes major policy actions in Europe. Toronto, 29.jun. Disponível em: http://www.g20.utoronto.ca/2012/2012-0629-finance.html. Acesso em: 5.jun.2014.

Group of Eight. 2012. Camp David Declaration. Maryland, 19.maio. Disponível em: http://www.g8.utoronto.ca/summit/ 2012campdavid/g8-declaration.html. Acesso em: 5.jun.2014.

Group of Twenty. 2008. Cúpula de líderes: mercados financeiros e economia mundial. Washongton, D.C., 15.nov. Disponível em: http://www.g7.utoronto.ca/g20/2008/2008declaration1115-br.html. Acesso em: 2.jun.2014. . 2009a. Declaração dos líderes do G20 em Londres. Londres, 2.abr. Disponível em: http://www.g7.utoronto.ca/g20/ 2009/2009communique0402-br.html. Acesso em: 2.jun.2014. 2009b. Declaração dos líderes: Cúpula de Pittsburgh - Arcabouço para o Crescimento Forte, Sustentável e Equilibrado. Disponível em: http://www.g7.utoronto.ca/g20/2009/2009communique0925-br.html. Acesso em: 2.jun.2014. . 2010a. The G20 Toronto Summit Declaration: Strong, Sustainable and Balanced Growth. Toronto, 26-27.jun. Disponível em: http://www.g7.utoronto.ca/g20/2010/g20_declaration_en.pdf. Acesso em: 5.jun.2014.

. 2010b. Enhancing the Legitimacy, Credibility and Effectiveness of the IFIs and further Supporting the Needs of the Most Vulnerable. Disponível em: http://www.g7.utoronto.ca/g20/2010/g20_declaration_en.pdf. Acesso em 5.maio.2014. em: 07/12/2010.

.2010c. The Seoul Summit Document. Disponível em: http://www.g7.utoronto.ca/g20/2010/g20seoul-doc.pdf. Acesso em: 5.jun.2014.

. 2010d. Seoul Development Consensus for Shared Growth.11-12.nov. Disponível em: http://www.g7.utoronto.ca/g20/ 2010/g20seoul-consensus.pdf. Acesso em: 5.jun.2014.

2011a. Cannes Summit Final Declaration - Building Our Common Future: Renewed collective action for the benefit of all. Cannes, 4.nov. Disponível em: http://www.g20.utoronto.ca/2011/2011-cannes-declaration-111104-en.html. Acesso em: 5.jun.2014.

. 2011b. Communiqué: G20 Leaders Summit. Cannes, 3-4.nov. Disponível em: http://g20civil.com/documents/Cannes_ Leaders_Communiqu_\%204_November_2011.pdf. Acesso em: 5.jun.2013.

. 2011c. Cannes Action Plan for Growth and Jobs. Cannes,4.nov. Disponível em: http://www.g20.utoronto.ca/2011/ 2011-cannes-action-111104-en.html. Acesso em: 5.jun.2014.

. 2012a. G20 Leaders Declaration. Los Cabos,19.jun. Disponível em: http://www.g20.utoronto.ca/2012/2012-0619loscabos.html. Acessado em: 07/07/2012.

. 2012b. The Los Cabos Growth and Jobs Action Plan. Los Cabos,19.jun. Disponível em: http://www.g20.utoronto.ca/ 2012/2012-0619-loscabos-actionplan.html. Acesso em 5.jun.2014.

UNSTATS. 2010. United Nations Statistics Division. Disponível em: http://unstats.un.org/unsd/default.htm. Acesso em: 2.jun.2014.

Brasil e EUA se aliam no G-20 a favor de estímulos. 2011. Valor Econômico, 13.out.

Brasil vai defender controle de capitais. 2010. Valor Econômico, 8.nov.

BRICS rejeitam reduzir acumulação de reservas. 2011. Valor Econômico, 14.out.

Joint Statement by the International Monetary and Financial Committee and the Group of 20 Finance Ministers and Central Bank Governors on IMF Resources. 2012. IMF Press release, 12/144, 20.Apr. Disponível em: http://www.imf.org/ external/np/sec/pr/2012/pr12144.htm. Acesso em: 5.jun.2014.

\section{ABSTRACT}

In 2000, at the Okinawa Summit, the G8 started an outreach movement. In such process it was the first time that non-participants countries of G8 were involved in G8 summits as well as in pre-summit meetings. In such process the G8 Gleneagles summit, in 2005, was a point of reference, once it was the first time that a document made by Brazil, India, China, South Africa and Mexico (BICSAM) - the Outreach Five (O5) or Group of Five (+5). Such engagement between such countries focusing the G8 occurred until the G8 L'Aquila Summit, in 2009. Nevertheless, once the G20 starts to cope with such themes as a leader's summit since 2008 and the BRIC(S) countries started to meet as a summit since 2009, such parallel engagement lost its relevance. In this context, a question that emerges concerns to the relationship between BRICS and the G20. How such bloc engages with this forum? what is its impact to decisions adopted in such forum? What is the relevance of China in such process? Questions like these are relevant once many approaches about G20 and emerging middle powers talks about the G20 legitimacy and responsiveness with little attention to emerging middle powers, their coalitions, blocs and engagement with the G20. Hence, the aim of the article is to point some of the principal questions concerning BRICS engagement with G20, its potentials and limitations.

KEYWORDS: BRICS; G20; global governance; FSB; G7/8. 